\title{
The Impact of Tobacco Control Policies on Smoking Initiation in Europe
}

Jan (J.C.) van Ours ${ }^{1}$

Ali Palali ${ }^{2}$

1: Erasmus School of Economics; Tinbergen Institute, The Netherlands

2: CPB 
Tinbergen Institute is the graduate school and research institute in economics of Erasmus University Rotterdam, the University of Amsterdam and VU University Amsterdam.

Contact: discussionpapers@tinbergen.nl

More TI discussion papers can be downloaded at the Tinbergen Site

Tinbergen Institute has two locations:

Tinbergen Institute Amsterdam

Gustav Mahlerplein 117

1082 MS Amsterdam

The Netherlands

Tel.: +31(0)20 5984580

Tinbergen Institute Rotterdam

Burg. Oudlaan 50

3062 PA Rotterdam

The Netherlands

Tel.: +31(0)10408 8900 


\title{
The Impact of Tobacco Control Policies on Smoking Initiation in Europe
}

\author{
Ali Palali * and Jan C. van Ours ${ }^{\dagger}$
}

August 3, 2017

\begin{abstract}
Our paper investigates the effect of tobacco control policies on smoking initiation in eleven European countries. We analyze longitudinal data of individuals by using information about their age of onset of smoking. We apply hazard rate models to study smoking initiation. Thus, we are able to take into account observed and unobserved personal characteristics as well as the effect of the introduction of a variety of tobacco control policies including bans on tobacco advertisements, smoke-free air regulation, health warnings on packages of cigarettes and treatment programs to help smokers quitting. We find that none of these tobacco control policies influence smoking initiation.
\end{abstract}

Keywords: tobacco control policies, smoking initiation, hazard rate models.

JEL classification codes: I12; C41

\footnotetext{
${ }^{*}$ CPB Netherlands Bureau for Economic Policy Analysis, The Hague, The Netherlands; Department of Economics, CentER, Tilburg University, The Netherlands; a.palali@cpb.nl

${ }^{\dagger}$ Erasmus School of Economics, Erasmus University Rotterdam, The Netherlands; Department of Economics, University of Melbourne, Australia; Tinbergen Institute (Amsterdam/Rotterdam) and CEPR (London); email: vanours@ese.eur.nl.
} 


\section{Introduction}

According to the World Health Organization tobacco use is an epidemic. In the past decades a large amount of evidence has piled up about the adverse health consequences of tobacco use (Levine et al. (1997)). These health effects have recently reached an alarming peak, which makes tobacco use one of the biggest health threats ever, killing approximately one person every six seconds (Mathers et al. (2012)). Nearly 6 million people die every year because of tobacco related diseases, a number which is expected to reach 8 million by 2030 .

The gloomy health effects have stimulated many governments to influence tobacco use through tobacco control policies. First and foremost, smoking is discouraged through high prices through substantial taxes on tobacco products. There are also non-price tobacco control policies ranging from prohibition or restriction of advertisements of cigarettes (or in general any tobacco products) to laws necessitating the placement of health warnings on tobacco product packages, and from different types of anti-smoking campaigns to laws prohibiting the use of tobacco in certain places. Nearly one third of the world's population is covered by at least one type of comprehensive non-price tobacco control policy and a considerable amount of resources is spent to enforce these policies (WHO (2013)).

To what extent tobacco control policies actually affect smoking is an empirical question. Past research on the effects of tobacco control policies is not conclusive. Whereas tobacco prices, bans on cigarette advertisements and placement of health warnings on tobacco and cigarette packages seem to have had a negative effect on the number of smokers and the per capita cigarette consumption, this is less clear for smoking bans, i.e. restrictions on smoking in public places and workplaces. Some studies find a negative effect on smoking, while others find no effect.

Most studies focus on the extensive or intensive margin of smoking, i.e. on the share of smokers in a population or the tobacco consumption per smoker. From a policy point of view, it is also important to assess the effects of tobacco control policies on smoking initiation. Early initiation has important effects later on in 
life. Van Ours (2006) shows that the age of onset of tobacco use is an important predictor of life-time tobacco use. An individual who starts smoking at an early age has a higher probability of long-term tobacco use compared to someone who starts later. This, in return, can increase the accumulated adverse effects later in life. Since the age of onset is a very strong predictor of addiction and quit behavior, analyzing the effects on smoking initiation is important not only for early smoking behavior, but also for smoking dynamics in general. The implicit assumption behind policies targeting youth's smoking is that reducing smoking initiation at a young age reduces lifetime smoking propensities (Glied (2002)).

In our analysis, we analyze Eurobarometer data from Austria, Germany, Finland, France, Ireland, Italy, the Netherlands, Portugal, Spain, Sweden and United Kingdom to study the effects of tobacco control policies on smoking initiation. We consider the effect of tobacco prices but also study the effects of non-price tobacco control policies in particular smoke-free air laws, bans on advertising promotion and sponsorship, health warnings on tobacco product packaging and smoking cessation treatment policies. The 11 European countries differ in the timing of introduction of these policies. To analyze the effects of tobacco control policies on smoking initiation, we use mixed proportional hazard rate models, which control for observed as well as unobserved determinants of smoking initiation.

Our study has three contributions to the literature on the effects of tobacco control policies. First, although there are several studies on the effect of tobacco control policies on adult and youth cigarette consumption, we contribute to the small literature about the effects of tobacco control policies on smoking initiation. Second, we present one of the first studies using individual level cross-country data, capturing the variation in the implementation of various tobacco control policies in European countries. The cross-country variation enables us to study the causal effects of tobacco control policies in an international context. Third, we use hazard rate models in our empirical analysis. The dynamics in smoking behavior are rather complex. Individuals start smoking over only a limited age range. If they have not started smoking by their early twenties, they are very 
unlikely to start smoking later on. Using a hazard rate framework allows us to take these peculiarities into account.

The set up for the remainder of our paper is as follows. In Section 2 we provide an overview of previous empirical studies on the impact of tobacco control policies. We distinguish between studies focusing on the extensive and intensive margin of smoking and studies focusing on smoking dynamics. Section 3 presents information about tobacco control policies in Europe and discusses the data we use in the empirical analysis. Section 4 provides a simple theoretical model to explain how tobacco control policies may affect smoking initiation. Section 5 presents the set-up of our analysis and our parameter estimates. Our main finding is that non-price tobacco control policies do not influence smoking initiation. Section 6 concludes.

\section{Previous studies}

\subsection{Prevalence and intensity of smoking}

Tobacco advertisements aim to persuade youngsters to start smoking or past smokers to restart smoking. They also aim to reduce incentives for smokers to quit smoking, or increase amounts of cigarettes smoked (Warner (1986)). Cigarette advertisements can also influence public discussions about negative consequences of smoking causing people to think that negative effects are overrated (Chaloupka and Warner (2000)). In short, tobacco advertisements encourage smoking and thus bans on these advertisements aim to prevent this encouragement. Bans on advertisements are an important component of tobacco control policies. Saffer and Chaloupka (2000) analyze the effects of banning tobacco advertisements on per capita cigarette consumption in 22 OECD countries. They find that comprehensive laws prohibiting advertisements have strong effects on per capita cigarette consumption whereas non-comprehensive laws have limited effects. Blecher (2008) analyzes the effects of laws prohibiting cigarette advertisements in 30 developing 
countries finding that both comprehensive bans and limited bans have a significant negative impact on per capita cigarette consumption.

Other tobacco control policies are the placement of health warnings on tobacco and cigarette packages and general campaigns about the negative health consequences of smoking. Health warnings can affect smoking both at the intensive and the extensive margin, i.e. the number of cigarettes per smoker and the share of smokers in the population. Warnings convey direct information about adverse health effects of smoking. This may prevent young individuals from starting to smoke. Moreover, health warnings on cigarette packages may reduce the intensity of smoking or stimulate quitting from smoking. Using US time series information Meier and Licari (1997) analyze the effects of health warnings on smoking along with the effects of taxes. They find that health warnings on cigarette packages have small but significant negative effects on cigarette consumption. Chaloupka and Grossman (1996) state that anti-smoking campaigns have had significant negative effects on youth smoking at both the intensive and the extensive margin.

Restrictions on smoking in public places or workplaces can directly affect cigarette consumption by making it harder for people to smoke. Moreover, such restrictions can easily affect the perception of smoking. First, these restrictions might work as a reminder about the negative consequences of smoking, especially for young individuals. Second, young individuals are less likely to be exposed to passive smoking thanks to these restrictions. Absence of smokers can affect their perception of cigarette consumption, i.e. when youngsters are less often exposed to smokers they may experience this as confirmation of negative health consequences of smoking. Chaloupka and Wechsler (1997) find that in the US, smoking restrictions have negative effects on smoking at both the intensive margin and the extensive margin. They also find that age restrictions on the access to tobacco seem to have had little impact as the effectiveness of such laws depends on their enforcement. Powell et al. (2005) find strong negative effects of tobacco control policies on tobacco use. Adda and Cornaglia (2010) find that laws prohibiting smoking at workplaces do not have any effect on smoking prevalence or per capita 
cigarette consumption. However, they find that smoking bans in bars and restaurants have small but significant negative effects. Nagelhout et al. (2011) find that the workplace smoking ban introduced in the Netherlands in 2004 decreased smoking prevalence while the smoking ban in bars and restaurant introduced in 2008 did not have an effect. Anger et al. (2011) study the effects of smoking bans who were gradually introduced in all of Germany's federal states. Using a difference-indifferences approach they find that the smoke-free legislation on average did not affect smoking behavior. However, among visitors of bars and restaurants smoking and smoking intensity were reduced. Smoke-free legislation is primary aimed to protect non-smokers from the harm of second-hand smoking. However, this legislation may also induce smokers to quit smoking. Nagelhout et al. (2012) find mixed evidence for this. In England and Ireland smoke-free legislation may have stimulated quits from smoking while in the Netherlands this does not seemed to have been the case.

Smoke-free legislation is not necessarily beneficial for non-smokers. Possibly smoking bans in public places lead to more smoking at home. However, Mons et al. (2013) using data from Ireland, France, Germany and the Netherlands find no evidence for this. Del Bono et al. (2014) provide an overview of European studies on the effects of smoking bans on smoking behavior concluding that the evidence is mixed. They revisit the effects of the 2005 smoking ban in Italy showing that previous studies that focused on a before-after comparison overestimate the effect of the ban. From a difference-in-difference set-up it appears that the smoking ban had no impact on smoking behavior. Jones et al. (2015) study the effects of public smoking bans on smoking behavior exploiting the differential timing of the introduction of these bans in Scotland and England finding that they had limited short-run effects on both smoking prevalence and the total level of smoking. Boes et al. (2015) study the effect of a Swiss smoking ban in public venues. Because these bans were introduced in different regions at different moments in time they are able to use a difference-in-differences approach finding a negative effect on smoking rates one year after the implementation of the bans. In a recent study 
Cott et al. (2016) investigate the impacts of tobacco control policies finding that an increase in the tobacco taxes significantly reduced the tobacco consumption and increased the consumption of smoking cessation products. However, they also find that a smoke-free-air policy banning smoking in bars do not have any significant effects on the consumption of tobacco products. Finally, in a recent paper Kuehnle and Wunder (2017) study the health impact of smoking bans in public places in Germany. Taking advantage of the differences in times at which smoking bans were enforced in different regions, the authors show that smoking bans did not have any effect on self-reported health of smokers, whereas they increased the self-reported health of passive smokers.

\subsection{Smoking dynamics}

In addition to studies on prevalence and intensity of smoking, there are studies that focus on smoking dynamics. Lillard et al. (2013) argue that models of smoking initiation based on longitudinal data are more relevant to policy analysis than models of the prevalence of smoking at a particular moment in time because the decision to start smoking is different from the decision to continue smoking. Dynamics in smoking behavior have been studied by using hazard rate models of smoking initiation sometimes in combination with hazard rate models of quitting smoking. Initially, the studies on smoking dynamics focused on the effect of cigarette prices only. Douglas and Hariharan (1994) analyzing US data find that cigarette prices have no impact on smoking initiation. Forster and Jones (2001) analyze British data finding that taxes do not affect smoking initiation while they have a positive effects on the quit rates from smoking. Kidd and Hopkins (2004) analyzing Australian data find that tobacco prices affect the onset of smoking but not the quit rate. Using various US datasets Lillard et al. (2013) find that cigarette prices affect smoking initiation decisions. Douglas (1998) analyzing US data finds no evidence of cigarette prices affecting smoking initiation while quit rates increase with cigarette prices. 
Douglas (1998) is among the few studies investigating the effects of non-price tobacco control policies on the dynamics in smoking. He uses a state-specific smoking restrictiveness index and finds evidence that a more restrictive policy promotes quitting from smoking but does not deter the decision to start smoking. López Nicolás (2002) analyzes Spanish data to establish the price sensitivity of smoking dynamics finding that prices have a very small effect on the propensity to start smoking while an increase in the prices of the cheapest varieties of cigarettes encourages quitting from smoking. López Nicolás (2002) also finds that the ban on smoking adds and smoking bans introduced in some public transport media in 1984 did not affect smoking dynamics whereas the extension of the smoking bans to flights and intensified health warning campaigns a few years later seem to have had an effect on both starting and quitting. Finally, Marti (2014) estimates the dynamics of smoking in Switzerland using tobacco control spending as one of the explanatory variables and finding that these affect both smoking initiation and quitting from smoking.

\section{$3 \quad$ Smoking in Europe}

\subsection{Tobacco control policies and prevalence of smoking}

Nowadays, strict regulations on tobacco use are common. Only a few decades ago this was not the case. Up to the 1960s, there were almost no tobacco control policies, neither on smoking in the public domain nor on advertising, as knowledge about the negative health consequences of smoking was limited. In the United States, the 1964 Surgeon General's report gradually changed the public opinion about tobacco use when it became clear that there are several adverse health consequences related to smoking.

Also in Europe, concerns about negative health consequences of tobacco use started in the 1960s. However, this lead only to some minor regulations in a few countries that advocated smoking cessation and restricted advertisements on 
Table 1: Information about Tobacco Control Policies: First year in which a policy was implemented; Percentages of current smokers.

\begin{tabular}{lcccccc}
\hline & \multicolumn{3}{c}{ Introduction } & TCP & \multicolumn{3}{c}{ Current smokers } \\
& S & H & B & C & Males & Females \\
\hline Austria & 1994 & 1974 & 1994 & 2001 & 33 & 27 \\
Germany & 1971 & 1976 & 1976 & 1976 & 25 & 19 \\
Finland & 1991 & 1975 & 1990 & 1974 & 22 & 17 \\
France & 2001 & 1981 & 1973 & 1998 & 32 & 25 \\
Ireland & 1994 & 1990 & 1970 & 1991 & 21 & 18 \\
Italy & 1974 & 1992 & 1982 & 1983 & 28 & 17 \\
Netherlands & 1989 & 1989 & 1989 & 1995 & 29 & 22 \\
Portugal & 1982 & 1990 & 1982 & 2001 & 28 & 13 \\
Spain & 1987 & 1987 & 1993 & 1990 & 30 & 21 \\
Sweden & 1993 & 1973 & 1993 & 1969 & 17 & 16 \\
United Kingdom & 2003 & 1990 & 1989 & 1986 & 19 & 16 \\
\hline
\end{tabular}

$\mathrm{S}=$ Smoke-free air; $\mathrm{H}=$ Health warnings; $\mathrm{B}=$ Bans on advertisements; $\mathrm{C}=$ Cessation policies. Percentages of current smokers relate to the adult population. Information from 2014; source except Ireland: Eurostat. Source Ireland: National Tobacco Control Office.

tobacco. For a long time, economic interests dominated concerns over health consequences of smoking. The "golden years of tobacco" lasted until the mid1980s when the European Union (EU) started to implement restrictive tobacco control policies by passing legislation and making tobacco control policies a part of European Union law.

Table 1 shows that the first tobacco control policies implemented were mainly bans on advertisement and health warnings on packages. Among the 11 European countries in our empirical analysis, six had already passed some restrictive regulations on tobacco advertisements in 1985, five had done so a few years later. By 1990 almost all countries had meaningful restrictions on advertisement and health warnings on packages. The first country to implement any tobacco control policy was Sweden by passing a law restricting tobacco advertisements in 1969. The last country to implement any tobacco control policy was the Netherlands in 1989. The late introduction may be related to the Netherlands for a long time being the second largest producer of tobacco products and the second largest exporter of cigarettes. 
To establish how smoking initiation is affected by tobacco control policies, we use the Tobacco Control Policy Index (TCPI) as an indicator. The TCPI has four main components: smoke-free air laws, bans on advertising promotion and sponsorship, health warnings on tobacco product packaging and smoking cessation treatment policies. Nguyen et al. (2012) created the TCPI adopting the scoring system introduced by Joossens and Raw (2006). It allocates points to several components of each policy. Smoke-free air laws policy for example has four components: Bans in cafes and restaurants, bans in public transportation, bans in other public places and bans in workplaces. The overall index reflects the sum of the scores given to each of the four policies which themselves are sums of the scores given to each of the components (see Appendix B for details). Since the same scoring system is used for all countries, the index can be used for cross-country comparisons of the strictness of tobacco control policies. ${ }^{1}$

Figure 1a displays the evolution of the TCPI in 11 European countries from 1950 until 2010. Before 1969, the index remains at zero because there was no tobacco control policy in any of the 11 countries. After 1969 the index slightly increases in many countries, and after 1990 it starts increasing rapidly. There are significant differences between countries for all tobacco control policies as the first implementation dates and the levels of policy scores differ considerably. Such differences also exits in the tobacco prices. Figure $1 \mathrm{~b}$ displays the trends in real tobacco prices in 11 countries. Even though real prices of tobacco have been increasing over time in all countries, the increase is much steeper in some countries such as Finland and United Kingdom than it is in other countries.

The last two columns of Table 1 provide information about smoking prevalence, i.e. the percentages of smokers in the adult population. There are clear differences between countries and between males and females. For males, the highest smoking prevalence is in Austria, France and Spain, with more than $30 \%$ currently smoking. In Sweden and the UK less than $20 \%$ of the adult males smoke. For females, the

\footnotetext{
${ }^{1}$ Two countries can have the same score even though they apply different tobacco control policies. Therefore, we also separately analyze the effects of each of the four main components.
} 
Figure 1: Tobacco Control Policy index and tobacco prices in 11 European countries; 1950-2010

a. Tobacco Control Policy index

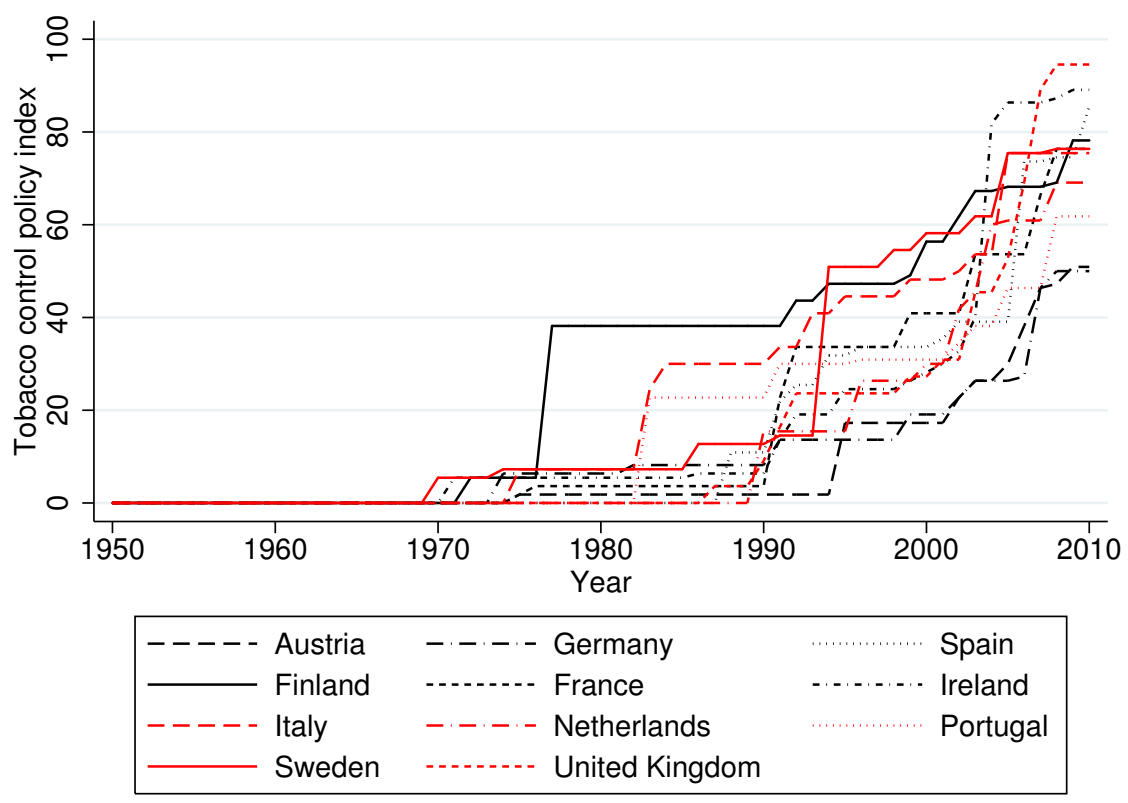

b. Tobacco prices

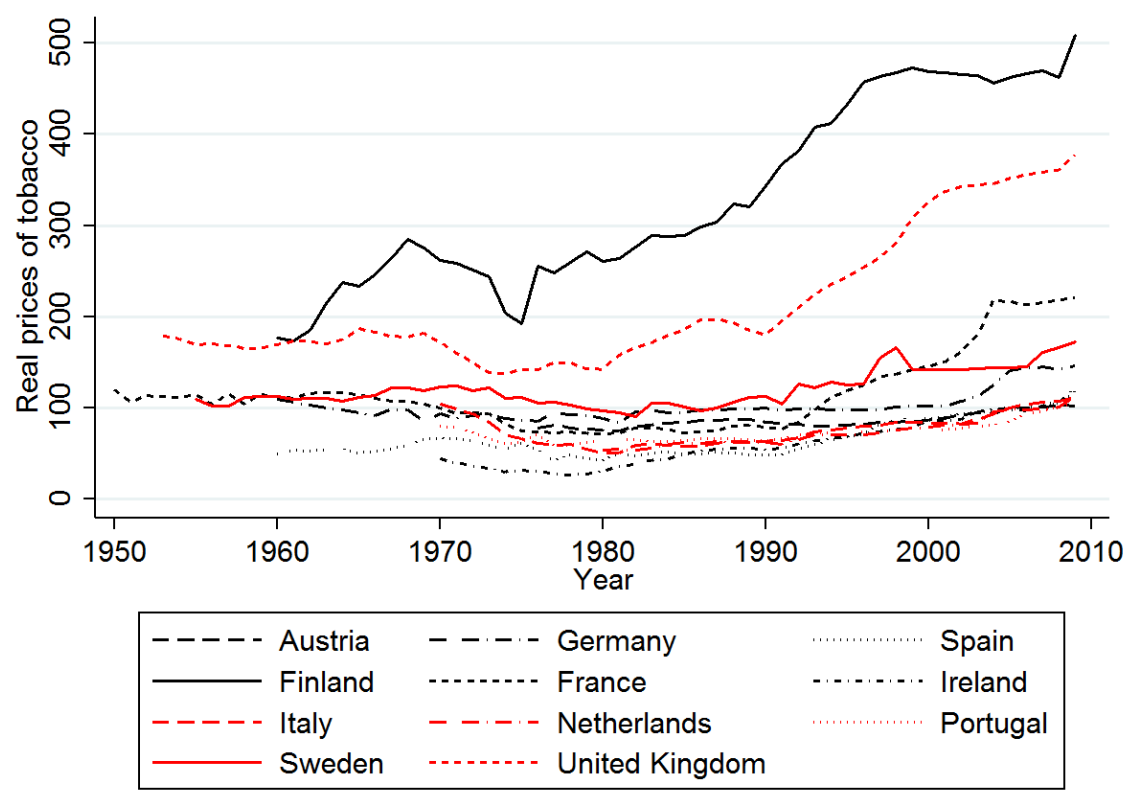

For Italy, Portugal and Spain the real price index is for tobacco, for the other countries the price index is for cigarettes. 
highest smoking prevalence of $25 \%$ or more is in Austria and France, the lowest with $13 \%$ is in Portugal. In all countries females are less likely to smoke than males although in Sweden the difference is only 1\%-point.

\subsection{Smoking initiation}

To study the uptake of smoking, we use data from the special Eurobarometer 429 covering residents in EU member states aged 15 years and over. These data collected in November/December 2014 through face-to-face interviews in people's homes focused on attitudes towards tobacco and electronic cigarettes. The starting point of the survey was the question "Regarding smoking cigarettes, cigars, cigarillos or a pipe, which of the following applies to you?"2 If the answer was "currently smoke" or "used to smoke but has stopped", the following question was "How old were you when you started smoking on a regular basis, i.e. at least once a week?" We use this retrospective information to reconstruct the history of smoking initiation necessary to model the starting rates of tobacco use.

Table 2: Cumulative probability to have started smoking by ages of 15, 20, 25 and 30 .

\begin{tabular}{lrlllrlll}
\hline & \multicolumn{1}{c}{ Females } & \multicolumn{1}{c}{ Males } \\
\hline Age & 15 & 20 & 25 & 30 & 15 & 20 & 25 & 30 \\
\hline Austria & 4 & 38 & 39 & 39 & 8 & 41 & 43 & 43 \\
Finland & 10 & 44 & 47 & 48 & 11 & 40 & 50 & 52 \\
France & 12 & 42 & 52 & 54 & 15 & 52 & 61 & 63 \\
Germany & 8 & 39 & 42 & 43 & 12 & 46 & 50 & 51 \\
Ireland & 6 & 34 & 39 & 39 & 7 & 33 & 40 & 41 \\
Italy & 3 & 24 & 33 & 35 & 7 & 32 & 37 & 37 \\
Netherlands & 14 & 42 & 48 & 49 & 16 & 44 & 49 & 54 \\
Portugal & 7 & 31 & 36 & 37 & 8 & 43 & 49 & 50 \\
Spain & 12 & 39 & 42 & 42 & 13 & 42 & 47 & 49 \\
Sweden & 7 & 29 & 37 & 38 & 10 & 35 & 40 & 41 \\
United Kingdom & 13 & 33 & 38 & 39 & 5 & 37 & 43 & 44 \\
\hline
\end{tabular}

Source: Authors' calculation.

The data we use are from 11 European countries for which we have information

\footnotetext{
${ }^{2}$ To this question was added that "Smoking cigarettes does not include use of electronic cigarettes."
} 
on tobacco control policies and tobacco prices. As Table 2 shows, the age pattern of smoking initiation is very similar across the countries. There is a strong increase between age 15 and 20, a slight increase between age 20 and 25 and a very small increase later on. However, there are big cross-country differences in cumulative starting probabilities by age 30. For males, the share of the population that has ever smoked or is still smoking ranges from $37 \%$ in Italy to $54 \%$ in the Netherlands. For females it ranges from $35 \%$ in Italy to $54 \%$ in France.

\section{A simple model of smoking initiation}

One of the challenges of modeling smoking initiation is to take into account that individuals start smoking in their teens or early twenties. If an individual has not started smoking in this age range, smoking initiation is very unlikely later on in life (Van Ours (2006)). This implies that over a relatively short age range individuals balance marginal costs and marginal benefits of smoking initiation and then decide whether or not to start smoking. Apparently, from a certain age onward, the balance is always negative, i.e. the marginal costs of smoking initiation are larger than the marginal benefits. Or, alternatively, individuals are no longer facing the balancing question as they already made up their mind that for the rest of their life it is better to abstain from smoking. It is also possible that for some individuals the costs of starting to smoke always outweighs potential benefits, i.e. they realize from early on in life that there are no utility gains in smoking initiation. And, it is also possible that later on in life individuals are no longer confronted with opportunities to start smoking because their friends, family and colleagues are non-smokers.

We present a simple model of smoking initiation with the purpose of illustrating how tobacco control policies may affect smoking initiation. We assume that individuals are confronted with a flow of smoking opportunities. ${ }^{3}$ The arrival rate

\footnotetext{
${ }^{3}$ This is similar to job finding theory where unemployed workers receive a stream of random wage offers from a distribution with certain characteristics. Conditional on the arrival rate of job offers, search costs and the wage distribution the individual decides which wage offers to accept.
} 
of smoking opportunities is likely to be age-dependent. According to Suranovic et al. (1999) individuals in their early teens have no or unknown benefits of smoking and therefore have no interest in starting to smoke. If friends start smoking and encourage participation, individuals understand that smoking has potential benefits. Furthermore, teenagers may experience peer pressure or follow the example of their parents. Conditional on having an opportunity to start smoking an individual will balance marginal benefits and marginal costs of doing so.

According to Douglas and Hariharan (1994) a rational individual will start smoking if and only if the marginal benefit of the first cigarette is larger than its marginal cost

$$
M B_{t}\left(C_{t}, Y_{t}, L_{t}\right)>M C_{t}\left(C_{t}, Y_{t}, L_{t}\right)
$$

where $C$ represents the consumption of a cigarette, $Y$ is the consumption of other goods, $L$ represents other life cycle events that affect utility, and $t$ represents time. ${ }^{4}$ Both marginal cost and marginal benefits may be influenced by variables that have a stochastic component. Therefore, equation 1 can be divided into a non-stochastic and a stochastic component:

$$
M B_{t}^{*}+\varepsilon_{t}>M C_{t}^{*}+\mu_{t}
$$

where $M B_{t}^{*}=E\left(M B_{t}\left(C_{t}, Y_{t}, L_{t}\right)\right)$ and $M C_{t}^{*}=E\left(M C_{t}\left(C_{t}, Y_{t}, L_{t}\right)\right)$. The probability of smoking initiation at time $t$ can be written as

$$
\begin{aligned}
\operatorname{Pr}\left(C_{t}>0\right) & =\operatorname{Pr}\left(M B_{t}^{*}+\varepsilon_{t}>M C_{t}^{*}+\mu_{t}\right) \\
& =\operatorname{Pr}\left(M B_{t}^{*}-M C_{t}^{*}>\mu_{t}-\varepsilon_{t}\right) \\
& =F\left(M B_{t}^{*}-M C_{t}^{*}\right)
\end{aligned}
$$

Of course there are many differences as well. Unemployed search for opportunities to make a transition from unemployment to work while non-smoking individuals may not be interested per se in a transition to becoming a smoker.

${ }^{4}$ Once an individual has started smoking, decisions to keep smoking later on depend on the stock of addictive capital based on the number of cigarettes smoked. Equation (1) is about smoking initiation, so the stock of addictive capital is zero. 
where $F$ is a distribution function. The probability of smoking at time $t$ conditional on not having smoked until time $t$ can also be written as a hazard function in which the opportunity arrival rate $\psi_{t}$ is taken into account.

$$
\theta(t)=\psi_{t} F\left(M B_{t}^{*}-M C_{t}^{*}\right)
$$

where $\theta(t)$ is the smoking initiation rate. As $M B_{t}^{*}-M C_{t}^{*}$ increases or the opportunity arrival rate goes up, the hazard rate of smoking initiation increases, and thus the probability to use tobacco increases.

To explain the pattern of smoking initiation from the mid teens to the early twenties one has to assume that the opportunity arrival rate has a peak in this age range or the difference between marginal benefits and marginal costs is positive only in this age interval. It may also be that opportunities are less likely to arrive for early teens or beyond early twenties. Perhaps peer groups are related to smoking behavior such that non-smokers hang-out or are partnered with nonsmokers and individuals who have never smoked are less likely to be confronted with an opportunity.

Orphanides and Zervos (1995) introduce heterogeneity across individuals on the basis of addictive tendencies. There are non-addicts and potential addicts. Before they start using an addictive good, individuals are uncertain about their addictive tendency. If an individual is of the addictive type (s)he will experience a negative utility effect related to the detrimental addictive side effects of past consumption. Individuals may fear to be of the addictive type and therefore abstain from starting to smoke. ${ }^{5}$ An alternative explanation for the observed age pattern of smoking initiation is that there is heterogeneity in individual behavior such that for some individuals marginal costs are always larger than marginal benefits and therefore they abstain from smoking. If for other individuals marginal benefits of

\footnotetext{
${ }^{5}$ Other individuals may start smoking, find out that they are of the addictive type and then regret their original decision. Regret may also have a different origin. Suranovic et al. (1999) for example assume bounded rationality such that individuals focus on decisions about current smoking rather than taking future smoking into account. Then, it is possible that later in life individuals regret decisions they made when they were young.
} 
smoking initiation are larger than marginal costs in the relevant age range, all these individuals will end up becoming smokers in their teens or early twenties. Then, the observed pattern of smoking initiation is caused by one group of individuals who all start smoking in the relevant age range and another group of individuals who abstain from smoking.

In our simple model of smoking initiation it is clear how tobacco control policies may influence decision making of individuals. Tobacco prices will increase marginal costs of smoking initiation and therefore reduce the probability that an individual will start smoking at a certain age. Individuals may take future tobacco prices into account as well. If so, this will affect the marginal costs more strongly. The nonprice tobacco control policies may affect marginal benefits and/or marginal costs of smoking initiation. All of these policies provide information about the negative health consequences of smoking and therefore increase the perceived marginal costs of smoking. In addition to this, smoke-free air laws may reduced marginal benefits of smoking as smoking is no longer possible in certain public domains. Bans on advertising promotion and sponsorship may be beneficial to early teens since without advertising they may not be aware of the pleasures that can be derived from being exposed to nicotine. Health warnings on tobacco product packaging will increase the perceived costs of smoking but may also reduce the marginal benefits of smoking as the pleasure derived from smoking may go down. Finally, smoking cessation treatment policies may be informative to non-smokers about potential addiction and therefore not only increase marginal costs but also reduce marginal benefits from smoking initiation.

\section{Empirical analysis}

\subsection{Set-up empirical analysis}

In our empirical analysis, we use a mixed proportional hazard model with a fully flexible baseline specification. Since the underlying dynamics of smoking initiation 
are expected to be gender-specific, we perform a separate analysis for males and females. In this set-up, the duration of stay in the non-smoking state is equivalent to the age of the individual where we assume that individuals are exposed to possible initiation to smoking from age 11 onward. The starting rate of smoking at time $t(t=0$ at age 11) of individual $i$ in country $j$ conditional on observed individual characteristics $x$, tobacco control policy index $B$, real tobacco price $P$ and unobserved individual characteristics $u$ is defined as

$$
\theta\left(t \mid x_{i}, B_{i j t}, P_{i j t}, u_{i}\right)=\lambda_{i}(t) \exp \left(x_{i}^{\prime} \beta+\delta B_{i j t}+\rho l o g\left(P_{i j t}\right)+u_{i}\right)
$$

where $\delta$ measures the effect of non-price tobacco control policies, $\rho$ measures the effect of prices, and $B_{i j t}$ and $P_{i j t}$ are time varying variables which captures the various levels of smoking restrictions and the variation in tobacco prices. Although within a country in a particular year the same smoking restrictions apply to all individuals in that country, the effect of a smoking restriction at a particular age depends on the year of birth of the individual. Therefore, the tobacco control policy at any given age is country-specific and individual-specific. Parameter $\rho$ measures the effect of tobacco prices where $\log \left(P_{i j t}\right)$ is the natural logarithm of the real prices of tobacco. Again, the calendar time variation in tobacco control policies is translated into age-specific variation because a change in tobacco control policy index in a particular year affects individuals from different birth years at a different age. The age variation in the tobacco control policies is country-specific since there is variation in the years in which these policies were introduced. Identification of the non-price tobacco control policies comes from cross-country variation in the timing of these policies and the cross-individual variation over age when these policies were implemented. In other words, we use a before-after approach in a hazard rate framework where the before-after variation is caused by the introduction of tobacco control policies in a particular year and in a particular country. This induces an age-specific shift in the starting rate of smoking. The observed characteristics $x$ refer to education, birth year and degree of urbanization of the place of 
residence (see Appendix A for details). The vector of parameters $\beta$ represents the effects of other control variables including country-specific birth year trends. Furthermore, $\lambda_{i}(t)$ represents individual duration dependence. As indicated before, we assume that everyone becomes vulnerable to the risk of initiation into smoking at age 11. This is because in all of the countries, almost no one starts using tobacco before the age of 11 . Because of this assumption, the duration dependence actually becomes age dependence. Finally, $u_{i}$ denotes unobserved heterogeneity in the starting rates of tobacco use. It controls for differences in time-invariant unobserved susceptibility of individuals to tobacco use. Note that the decision to start smoking often occurs before an individual obtains his or her final educational attainment. Therefore, we assume educational attainment to be an indicator of ability. By way of sensitivity analysis we also did estimates excluding educational attainment as an observed characteristic, finding similar results.

Duration dependence is specified in a fully flexible way by means of a step function

$$
\lambda_{i}(t)=\exp \left(\sum_{k} \lambda_{i k} I_{k}(t)\right)
$$

where $k(=1, . ., 11)$ is a subscript for age categories starting from age 11 and $I_{k}(t)$ are time-varying dummy variables that are one in subsequent categories, 10 of which are for individual ages or age intervals (age 11 and 12, .., 17, 18-19, 20-22) and the last interval is for ages above 22 years. Because we estimate a constant term in the analysis, we normalize $\lambda_{i, 1}=0$.

The conditional density function of the completed durations until the first use of tobacco can be written as

$$
f\left(t \mid x_{i}, B_{i j t}, P_{i j t}, u_{i}\right)=\theta\left(t \mid x_{i}, B_{i j t}, P_{i j t}, u_{i}\right) \exp \left(-\int_{0}^{t} \theta\left(s \mid x_{i}, B_{i j t}, P_{i j t}, u_{i}\right) d s\right)
$$

We integrate out the unobserved heterogeneity such that density function for the 
duration until tobacco uptake $t$ conditional on $x$ becomes

$$
f\left(\mid x_{i}, B_{i j t}, P_{i j t}\right)=\int_{u_{i}} f\left(t \mid x_{i}, B_{i j t}, P_{i j t}, u_{i}\right) d G\left(u_{i}\right)
$$

where $G(u)$ is assumed to be a discrete mixing distribution with 2 points of support $u_{1}$ and $u_{2}$. This reflects the presence of two types of individuals in the hazard rate for tobacco uptake. The associated probabilities are denoted as follows: $\operatorname{Pr}(u=$ $\left.u_{1}\right)=p$ and $\operatorname{Pr}\left(u=u_{2}\right)=1-p$, where $p$ is modeled using a logit specification,

$p=\frac{\exp (\alpha)}{1+\exp (\alpha)}$. Individuals who do not start using tobacco until the time of the survey are considered to have right-censored durations until smoking initiation. The inflow nature of the data guarantees that there are no left censored individuals.

\subsection{Baseline parameter estimates}

Table 3 presents our baseline parameter estimates obtained by the method of Maximum Likelihood. The first column presents the parameter estimates for males, the second column for females. Panel a of Table 3 contains the baseline parameter estimates in which we make no distinction between types of tobacco control policies focusing on the aggregate indicator for tobacco control policies. Parameter estimates of the country fixed effects, the country-specific birth year trends are not reported. Our main parameter of interest, related to the tobacco control policies index is negative and insignificant for both males and females. Tobacco prices have a negative effect for males but not for females. The age of onset of smoking goes up with tobacco prices for males but not for females. As to the personal characteristics, for males and females lower educational attainment has a positive effect on the smoking initiation rate. Higher education - which we assume to be an indication of ability - has a negative effect on the smoking initiation rate. Females in big cities have a higher starting rate. For males we do not find any effect for urbanization. The age dependence pattern reflects the age-related fluctuation in the smoking initiation rates. Parameter estimates for unobserved heterogeneity show that for both males and females there is unobserved heterogeneity in the 
Table 3: Parameter estimates mixed proportional hazard model

\begin{tabular}{|c|c|c|c|c|}
\hline & \multicolumn{2}{|c|}{ Males } & \multicolumn{2}{|c|}{ Females } \\
\hline \multicolumn{5}{|c|}{ a. Baseline: CS-BY; no CT } \\
\hline Tobacco control policies & -0.04 & $(0.8)$ & -0.05 & $(1.2)$ \\
\hline Tobacco prices & -0.01 & $(2.8)^{* *}$ & 0.00 & $(0.7)$ \\
\hline Education 2 & -0.72 & $(3.4)^{* *}$ & -0.63 & $(3.3)^{* *}$ \\
\hline Education 3 & -1.84 & $(8.4)^{* *}$ & -1.47 & $(7.2)^{* *}$ \\
\hline Education 4 & -2.20 & $(8.5)^{* *}$ & -1.56 & $(5.9)^{* *}$ \\
\hline Small/mid town & 0.17 & $(1.3)$ & 0.32 & $(2.2)^{* *}$ \\
\hline Large town & -0.01 & $(0.1)$ & 0.29 & $(2.2)^{* *}$ \\
\hline Age 12 & 0.37 & $(1.1)$ & 0.58 & $(1.6)$ \\
\hline Age 13 & 1.75 & $(5.4)^{* *}$ & 1.53 & $(4.4)^{* *}$ \\
\hline Age 14 & 2.52 & $(8.1)^{* *}$ & 2.40 & $(7.2)^{* *}$ \\
\hline Age 15 & 3.01 & $(9.6)^{* *}$ & 3.16 & $(9.5)^{* *}$ \\
\hline Age 16 & 3.47 & $(10.9)^{* *}$ & 3.81 & $(11.5)^{* *}$ \\
\hline Age 17 & 3.37 & $(10.2)^{* *}$ & 4.10 & $(11.9)^{* *}$ \\
\hline Age 18 & 3.60 & $(10.6)^{* *}$ & 4.41 & $(12.2)^{* *}$ \\
\hline Age 19 & 3.19 & $(8.8)^{* *}$ & 4.19 & $(10.6)^{* *}$ \\
\hline Age $20+$ & 1.27 & $(3.0)^{* *}$ & 2.04 & $(4.6)^{* *}$ \\
\hline$u_{2}$ & -3.19 & $(11.5)^{* *}$ & -3.84 & $(20.6)^{* *}$ \\
\hline$\alpha$ & 0.04 & $(0.3)$ & -0.75 & $(11.1)^{* *}$ \\
\hline -LogLikelihood & \multicolumn{2}{|c|}{3541.8} & \multicolumn{2}{|c|}{3962.9} \\
\hline \multicolumn{5}{|c|}{ b. Alternative specifications } \\
\hline \multicolumn{5}{|c|}{ 1. G-BY; no CT } \\
\hline Tobacco control policies & 0.06 & $(1.6)$ & -0.02 & $(0.1)$ \\
\hline Tobacco prices & -0.01 & $(1.8)^{*}$ & -0.00 & $(0.2)$ \\
\hline -LogLikelihood & \multicolumn{2}{|c|}{3553.0} & \multicolumn{2}{|c|}{3974.5} \\
\hline \multicolumn{5}{|l|}{ 2. CS-BY; G-CT } \\
\hline Tobacco control policies & -0.04 & $(0.7)$ & -0.05 & $(1.2)$ \\
\hline Tobacco prices & -0.02 & $(2.8)^{* *}$ & 0.01 & $(0.6)$ \\
\hline -LogLikelihood & \multicolumn{2}{|c|}{3541.8} & \multicolumn{2}{|c|}{3962.9} \\
\hline \multicolumn{5}{|l|}{ 3. GS-BY; CS-CT } \\
\hline Tobacco control policies & -0.03 & $(0.6)$ & -0.04 & $(0.8)$ \\
\hline -LogLikelihood & \multicolumn{2}{|c|}{3539.3} & \multicolumn{2}{|c|}{3955.7} \\
\hline Observations & \multicolumn{2}{|c|}{2065} & \multicolumn{2}{|c|}{2442} \\
\hline
\end{tabular}

All estimates contain country fixed effects; $\mathrm{G}=$ General; $\mathrm{CS}=$ Country-Specific; BY = Birth year trend; CT = Calendar Time trend; absolute t-statistics in parentheses; ** are for statistical significance at $5 \%$. 
starting to smoke rate. Among the males 54 percent has a high starting rate while 46 percent has a low starting rate. Among females these shares are 39 and 61 , respectively. The starting rate of the second group is much smaller than the starting rate of the first group. This implies that although some individuals have a positive probability to start smoking this probability is so small that they will never do that (see Abbring (2002) for a discussion on the distinction between ex ante abstainers and ex post abstainers.)

As a first check on the robustness of our findings, we estimated the same models with slightly different specifications. Panel b of Table 3 shows how the effect of the TCPI is influenced by changes in the specification of birth year and calendar time trend. In panel b1 the country-specific birth year trends are replaced by a common birth year trend. In panel b2 and b3 the country-specific birth year trends are reintroduced. In panel b2 a general calendar time trend is introduced; in panel b3 country-specific time trends are introduced. The parameter estimates of the TCPI are not very much affected. For males, replacing the country-specific birth year trends by a common birth year trend changes the sign of the TCPI parameter but this is still insignificantly different from zero. The introduction of a calender time trend irrespective of whether this is general or country-specific is not very important. For females all parameter estimates of the TCPI-index are very much the same, i.e. small and insignificantly different from zero.

\subsection{Sensitivity analysis}

To further investigate the robustness of our findings we performed a range of sensitivity analysis. In panel a of Table 4 we report the effects of particular types of tobacco control policies: smoke-free air laws, bans on advertising promotion and sponsorship, health warnings on tobacco product packaging and smoking cessation treatment policies. Both for males and females, none of the separate tobacco control policies had an effect on the age of initiation to smoking.

Panel b of Table 4 presents further sensitivity outcomes. In panels b1 to b3 the tobacco control policy index is replaced by a dummy variable. In panel b1 the 
Table 4: Parameter estimates effect tobacco control policies; sensitivity analysis

\begin{tabular}{|c|c|c|c|c|c|c|}
\hline & \multicolumn{2}{|c|}{ Males } & $-\log L$. & \multicolumn{2}{|c|}{ Females } & $-\log \mathrm{L}$. \\
\hline \multicolumn{7}{|l|}{ a. Type of TCP } \\
\hline 1. Smoke-free & -0.03 & $(0.8)$ & 3541.8 & -0.01 & $(0.5)$ & 3963.5 \\
\hline 2. Advertising & 0.01 & $(0.2)$ & 3542.1 & -0.02 & $(0.2)$ & 3963.0 \\
\hline 3. Health warnings & -0.03 & $(0.6)$ & 3541.9 & -0.01 & (1.4) & 3963.2 \\
\hline 4. Cessation & -0.05 & $(1.1)$ & 3541.5 & -0.05 & $(1.5)$ & 3963.3 \\
\hline \multicolumn{7}{|c|}{ b. Additional sensitivity analysis } \\
\hline 1. Any TCP & 0.03 & $(1.5)$ & 3541.2 & -0.08 & $(0.4)$ & 3963.3 \\
\hline 2. Bans in public places & -0.01 & $(0.1)$ & 3542.1 & 0.02 & $(0.2)$ & 3963.3 \\
\hline 3. Bans in workplaces & -0.01 & $(0.2)$ & 3542.2 & 0.02 & $(1.5)$ & 3962.5 \\
\hline 4. Birth year from 1960 & -0.04 & $(0.7)$ & 6028.2 & -0.02 & $(0.6)$ & 4734.6 \\
\hline 5. Birth year from 1950 & -0.03 & $(0.2)$ & 4647.4 & -0.04 & $(1.0)$ & 4187.8 \\
\hline
\end{tabular}

\begin{abstract}
All estimates contain country fixed effects, country-specific birth year trends, and a general time trend as well as the other individual characteristics presented in Table 3. The estimates and panel a and b1-b3 are based on 2065 males and 2442 females. In estimation b4, the numbers of observations are 2815 for males and 3075 for females; countries excluded due to the unavailability of the price information are Austria and the Netherlands. In estimation b5, the numbers of observations are 2270 for males and 2297 for females; countries excluded due to the unavailability of the price information are Austria, Ireland, Italy, Portugal and the Netherlands
\end{abstract}

dummy variable is 1 if any tobacco control policy is implemented. In panel b2 it is 1 if smoking is banned in public places, in estimation b3 it is 1 if smoking is banned in workplaces. Therefore, in these estimations we compare the age of onset of smoking for individuals before and after a tobacco control policy is implemented. The parameter estimates show that our conclusion remains the same. In panels b4 and b5 we also use information on older cohorts, those who were born after 1959 and after 1949, respectively. In some countries the information on tobacco prices is not available for early years, in which case we exclude these countries from this part of the analysis. In panel b4, countries excluded due to the unavailability of the price information are Austria and the Netherlands. In panel b5, Austria, Ireland, Italy, Portugal and the Netherlands are excluded. Although the sample sizes and cohort structure considerably change, our conclusions remain same. This sensitivity analysis also shows that a possible recall bias due to the self-reporting of the data is not an issue. 


\section{Conclusions}

In the past decades, many countries introduced non-price tobacco control policies to reduce smoking. Empirical evidence on the effectiveness of such policies on smoking behavior is inconclusive in the sense that some studies find that tobacco control policies reduce smoking while other studies find no effect. These differences in findings are partly due to differences in methodology. Many studies use a repeated cross-section type of approach in which the incidence of smoking or the intensity of smoking is the dependent variable. The effect of a tobacco control policy is analyzed by studying calendar time variation in these smoking variables. Sometimes, studies exploit cross-regional or cross-state differences in the introduction of a tobacco control policy. If an effect is found on the incidence of smoking it is not clear whether this a caused by a decrease in the uptake of smoking or an increase in the quitting from smoking. If an effect is found on the intensity of smoking it is not always clear whether the incidence of smoking is affected as well. There are also a few studies that focus on the dynamics in smoking, studying the effects of tobacco control policies on the uptake of smoking sometimes in combination with the effect on the quitting from smoking.

Our paper contributes to the literature on the relationship between tobacco control policies and smoking initiation. We analyze the effects of tobacco control policies on the age of onset of smoking in 11 European countries which implemented different tobacco control policies in different years. We analyze the overall impact of tobacco control policies and study the separate components of these policies, i.e. smoke-free air laws, bans on advertising promotion and sponsorship, health warnings on tobacco product packaging and smoking cessation treatment policies. In our empirical analysis, we use mixed proportional hazard rate models to control for observed as well as unobserved factors that can affect smoking initiation. Our model allows a tobacco control policy which is introduced in a particular calendar year to influence the starting rate of smoking through a shift in the smoking initiation rate. The smoking initiation rate is allowed to be country-specific while 
we allow for cross-country differences in birth-year trends.

We find that the starting rate of smoking decreases with educational attainment, is age-specific and for males we find that it decreases with tobacco prices. Our main result is that non-price tobacco control policies have no significant effect on the age of onset of smoking, neither for males nor for females. Current tobacco control policies do not seem to discourage young individuals from starting to smoke. This does not imply that current tobacco control policies are all together ineffective in reducing smoking since they could have reduced the intensity of smoking or stimulated the quit rate from smoking. Nevertheless, our main findings are alarming because preventing young people from starting to smoke should be as important as trying to reduce their consumption or trying to convince them to quit once they have started. Thus, special tobacco control policies need to be designed to prevent youngsters from starting to smoke. This can help governments in their fight against tobacco use in the general population. 


\section{References}

Abbring, J. H. (2002). Stayers versus defecting movers: a note on the identification of defective duration models. Economics Letters 74, 327-331.

Adda, J. and F. Cornaglia (2010). The effect of bans and taxes on passive smoking. American Economic Journal: Applied Economics 2(1), 1-32.

Anger, S., M. Kvasnicka, and T. Siedler (2011). One last puff? Public smoking bans and smoking behavior. Journal of Health Economics 30(3), 591-601.

Blecher, E. (2008). The impact of tobacco advertising bans on consumption in developing countries. Journal of Health Economics 27(4), 930 - 942.

Boes, S., J. Marti, and J. C. Maclean (2015). The impact of smoking bans on smoking and consumer behavior: quasi-experimental evidence from Switzerland. Health Economics 24(11), 1502-1516.

Chaloupka, F. and M. Grossman (1996). Price, tobacco control policies and youth smoking. National Bureau of Economic Research. Working Paper No 5740.

Chaloupka, F. and K. Warner (2000). The economics of smoking. In A. J. Culyer and J. P. Newhouse (Eds.), Handbook of Health Economics, Volume 1, Chapter 29, pp. 1539-1627. Elsevier.

Chaloupka, F. and H. Wechsler (1997). Price, tobacco control policies and smoking among young adults. Journal of Health Economics 16(3), 359-373.

Cott, C., E. Nesson, and N. Tefft (2016). The effects of tobacco control policies on tobacco products, tar, and nicotine purchases among adults: Evidence from household panel data. American Economic Journal: Economic Policy 8(4), 103-123.

Del Bono, E., K. Grünberger, and D. Vuri (2014). Seasonality in smoking behaviour: Re-evaluating the effects of the 2005 public smoking ban in Italy. Working paper series no. 5083. CESifo.

Douglas, S. (1998). The duration of the smoking habit. Economic Inquiry 36, 49-64.

Douglas, S. and G. Hariharan (1994). The hazard of starting smoking: estimates from a split population duration model. Journal of Health Economics 13, 213-230.

Forster, M. and A. Jones (2001). The role of tobacco taxes in starting and quitting smoking: duration analysis of British data. Journal of the Royal Statistical Society A $164,517-547$.

Glied, S. (2002). Youth tobacco control: reconciling theory and empirical evidence. Journal of Health Economics 21(1), 117 - 135. 
Jones, A., A. Laporte, N. Rice, and E. Zucchelli (2015). Do public smoking bans have an impact on active smoking? Evidence from the UK. Health Economics 24, 175-192.

Joossens, L. and M. Raw (2006). Tobacco control scale: a new scale to measure country activity. Tobacco Control 15, 247-253.

Kidd, M. and S. Hopkins (2004). The hazard of starting and quitting smoking: some Australian evidence. Economic Record 80, 177-192.

Kuehnle, D. and C. Wunder (2017). The effects of smoking bans on self-assessed health: Evidence from Germany. Health Economics 26, 321-337.

Levine, P. B., T. A. Gustafson, and A. D. Velenchik (1997). More bad news for smokers? The effects of cigarette smoking on wages. Industrial and Labor Relations Review 50(3), 493-509.

Lillard, D., E. Molloy, and A. Sfekas (2013). Smoking initiation and the iron law of demand. Journal of Health Economics 32(1), 114-127.

López Nicolás, A. (2002). How important are tobacco prices in the propensity to start and quit smoking? An analysis of smoking histories from the Spanish National Health Survey. Health Economics 11, 521-535.

Marti, J. (2014). The impact of tobacco control expenditures on smoking initiation and cessation. Health Economics 23, 1397-1410.

Mathers, C., G. Stevens, E. Tursan, and L. Wolfenden (2012). Mortality attributable to tobacco. Geneva: World Health Organization.

Meier, K. and M. Licari (1997). The effect of cigarette taxes on cigarette consumption, 1955 through 1994. American Journal of Public Health 87, 1126-1130.

Mons, U., G. Nagelhout, S. Allwright, R. Guignard, B. van den Putte, M. Willemsen, G. Fong, H. Brenner, M. Pötschke-Langer, and L. Breitling (2013). Impact of national smoke-free legislation on home smoking bans: findings from the International Tobacco Control Policy Evaluation Project Europe Surveys. Tobacco Control 22, e1-e9.

Nagelhout, G., H. de Vries, C. Boudreau, S. Allwright, A. McNeill, B. van den Putte, G. Fong, and M. Willemsen (2012). Comparative impact of smoke-free legislation on smoking cessation in three European countries. European Journal of Public Health 22, Supplement 1, 4-9.

Nagelhout, G., M. Willemsen, and H. de Vries (2011). The population impact of smokefree work and hospitality industry legislation on smoking behaviour. Findings from a national population survey. Addiction 106, 816-823. 
Nguyen, L., G. Rosenqvist, and M. Pekurinen (2012). Demand for Tobacco in Europe An Econometric Analysis of 11 Countries for the PPACTE Project. Helsinki: National Institute for Health and Welfare.

Orphanides, A. and D. Zervos (1995). Rational addiction with learning and regret. Journal of Political Economy 103(4), 739-758.

Powell, L. M., J. A. Tauras, and H. Ross (2005). The importance of peer effects, cigarette prices and tobacco control policies for youth smoking behavior. Journal of Health Economics 24(5), 950 - 968.

Saffer, H. and F. Chaloupka (2000). The effect of tobacco advertising bans on tobacco consumption. Journal of Health Economics 19(6), 1117 - 1137.

Suranovic, S. M., R. S. Goldfarb, and T. C. Leonard (1999). An economic theory of cigarette addiction. Journal of Health Economics 18(1), 1 - 29.

Van Ours, J. C. (2006). Dynamics in the use of drugs. Health Economics 15(12), $1283-1294$.

Warner, K. (1986). Selling Smoke: Cigarette advertising and public health. American Public Health Association: Washington.

WHO (2013). Report on the global tobacco epidemic. Geneva: World Health Organization. 


\section{Appendix A: Details on our data}

Definition of variables:

- Education: Measured in terms of age when the respondent left formal education: No education/still studying, up to 15, up to 20, older than 20.

- Cohort effect (age): Age of the respondent in the survey year to capture the cohort effects.

- Urbanization dummies: Rural town/village, small/mid town, large town.

The table below provides descriptives.

\begin{tabular}{|c|c|c|c|c|c|c|}
\hline & \multicolumn{3}{|c|}{ Females } & \multicolumn{3}{|l|}{ Males } \\
\hline & Mean & Min & Max & Mean & Min & $\operatorname{Max}$ \\
\hline Birth year-1900 & 81.4 & 69 & 99 & 82.1 & 69 & 99 \\
\hline \multicolumn{7}{|l|}{ Education dummies: } \\
\hline 1. No education/Still studying & 0.17 & 0 & 1 & 0.19 & 0 & 1 \\
\hline 2. Up to 15 & 0.07 & 0 & 1 & 0.06 & 0 & 1 \\
\hline 3. Up to 20 & 0.38 & 0 & 1 & 0.37 & 0 & 1 \\
\hline 4. Older than 20 & 0.38 & 0 & 1 & 0.38 & 0 & 1 \\
\hline \multicolumn{7}{|l|}{ Urbanization dummies: } \\
\hline Rural town/village & 0.26 & 0 & 1 & 0.25 & 0 & 1 \\
\hline Small/Mid town & 0.44 & 0 & 1 & 0.43 & 0 & 1 \\
\hline Large town & 0.30 & 0 & 1 & 0.32 & 0 & 1 \\
\hline Austria & 0.12 & 0 & 1 & 0.09 & 0 & 1 \\
\hline Germany & 0.13 & 0 & 1 & 0.13 & 0 & 1 \\
\hline Finland & 0.07 & 0 & 1 & 0.07 & 0 & 1 \\
\hline France & 0.08 & 0 & 1 & 0.08 & 0 & 1 \\
\hline Ireland & 0.11 & 0 & 1 & 0.09 & 0 & 1 \\
\hline Italy & 0.09 & 0 & 1 & 0.10 & 0 & 1 \\
\hline Netherlands & 0.07 & 0 & 1 & 0.07 & 0 & 1 \\
\hline Portugal & 0.10 & 0 & 1 & 0.08 & 0 & 1 \\
\hline Spain & 0.09 & 0 & 1 & 0.09 & 0 & 1 \\
\hline Sweden & 0.05 & 0 & 1 & 0.11 & 0 & 1 \\
\hline United Kingdom & 0.08 & 0 & 1 & 0.09 & 0 & 1 \\
\hline
\end{tabular}

Based on 2065 males and 2442 females. 


\section{Appendix B: The Tobacco Control Policy Index}

\begin{tabular}{|c|c|c|c|}
\hline & & Total & Rebased \\
\hline 1 & Smoke-free air & 22 & 40 \\
\hline \multirow[t]{5}{*}{ A. } & Cafes and restaurants - one only of: & 8 & 14.55 \\
\hline & Complete ban, enforced & 8 & 14.55 \\
\hline & Complete ban, but with closed, ventilated, designated smoking rooms; enforced & 6 & 10.91 \\
\hline & Meaningful restrictions; enforced & 4 & 7.27 \\
\hline & Legislation, but not enforced & 2 & 3.64 \\
\hline \multirow[t]{3}{*}{ B. } & Public transport - additive: & 2 & 3.645 \\
\hline & Complete ban in domestic trains without exceptions & 1 & 1.82 \\
\hline & Complete ban in other public transport without exceptions & 1 & 1.82 \\
\hline \multirow[t]{3}{*}{ C. } & Other public places & 2 & 3.64 \\
\hline & $\begin{array}{l}\text { Complete ban in educational, health, government and cultural places, without } \\
\text { exception OR }\end{array}$ & 2 & 3.64 \\
\hline & $\begin{array}{l}\text { Ban in education, health, government, cultural places, with designated smoking } \\
\text { areas or rooms }\end{array}$ & 1 & 1.82 \\
\hline \multirow[t]{6}{*}{ D. } & Workplaces excluding cafes and restaurants - one only of & 10 & 18.18 \\
\hline & Complete ban without exceptions (no smoking rooms); enforced & 10 & 18.18 \\
\hline & Complete ban, but with closed, ventilated, designated smoking rooms; enforced & 8 & 14.55 \\
\hline & Complete ban, but with ventilated, designated smoking rooms; enforced & 6 & 10.91 \\
\hline & Meaningful restrictions; enforced & 4 & 7.27 \\
\hline & Legislation, but not enforced & 2 & 3.64 \\
\hline 2 & Comprehensive bans on advertising and promotion & 13 & 23.64 \\
\hline A. & Complete ban on tobacco advertising on television & 3 & 5.45 \\
\hline B. & Complete ban on outdoor advertising (e.g. posters) & 2 & 3.64 \\
\hline C. & Complete ban on advertising in print media (e.g. Newspapers and magazines) & 2 & 3.64 \\
\hline \multicolumn{4}{|c|}{ D. Complete ban on indirect advertising (e.g. cigarette branded clothes, etc) } \\
\hline E. & Ban on point of sale advertising & 1 & 1.82 \\
\hline F. & Ban on cinema advertising & 1 & 1.82 \\
\hline G. & Ban on sponsorship & 1 & 1.82 \\
\hline H. & Ban on internet advertising & 0.5 & 0.91 \\
\hline I. & Ban on radio advertising & 0.5 & 0.91 \\
\hline 3 & Large direct health warning labels & 10 & 18.18 \\
\hline A. & Rotating health warnings & 2 & 3.64 \\
\hline \multirow[t]{5}{*}{ B. } & Size of warning - one only of: & 4 & 7.27 \\
\hline & $10 \%$ or less of packet & 1 & 1.82 \\
\hline & $11-25 \%$ of packet & 2 & 3.64 \\
\hline & $26-40 \%$ of packet & 3 & 5.45 \\
\hline & $41 \%$ or more of packet & 4 & 7.27 \\
\hline C. & Contrasting color (e.g. Black lettering on white background) & 1 & 1.82 \\
\hline D. & A picture or graphic image & 3 & 5.45 \\
\hline 4 & Treatment to help dependent smokers stop & 10 & 18.18 \\
\hline \multirow[t]{3}{*}{ A. } & Quit-line - one only of: & 2 & 3.64 \\
\hline & Well funded national quit-line or well funded quit-lines in all major regions & 2 & 3.64 \\
\hline & National quit-line with limited funding or a patchwork of small local quit-lines & 1 & 1.82 \\
\hline \multirow[t]{10}{*}{ B. } & Network of smoking cessation support (3) and reimbursement of treatment (3) & 6 & 10.91 \\
\hline & Covering whole country $(3)$; free $(3)$ & 6 & 10.91 \\
\hline & Only in selected areas (e.g. Major cities) (2); free (3) & 5 & 9.09 \\
\hline & Covering whole country (3); cost partially covered (2) & 5 & 9.09 \\
\hline & Very limited, just a few centers $(1)$, free $(3)$ & 4 & 7.27 \\
\hline & Only in selected areas (e.g. Major cities) (2), costs partially covered (2) & & \\
\hline & Covering whole country $(3)$; not free $(0)$ & 3 & 5.45 \\
\hline & Very limited, just a few centers (1), costs partially covered (2) & 3 & 5.45 \\
\hline & Only in selected areas (e.g. Major cities) (2), not free (0) & 2 & 3.64 \\
\hline & Just a few centers $(1)$, not free $(0)$ & 1 & 1.82 \\
\hline \multirow[t]{4}{*}{ C. } & Reimbursement of medications - one only of: & 2 & 3.64 \\
\hline & Reimbursement of pharmaceutical treatment products & 2 & 3.64 \\
\hline & Partial reimbursement of pharmaceutical treatment products & 1 & 1.82 \\
\hline & Total score & 55 & 100 \\
\hline
\end{tabular}




\section{Appendix C: Not for publication}

This appendix contains a number of country-specific graphs. Figure 2 shows the evolution of the TCPI over time. Figure 3 shows the starting rates and cumulative starting probabilities by age, separately for males and females. 
Figure 2: Separate indexes of tobacco control policies in 11 European countries; $1950-2010$

Austria

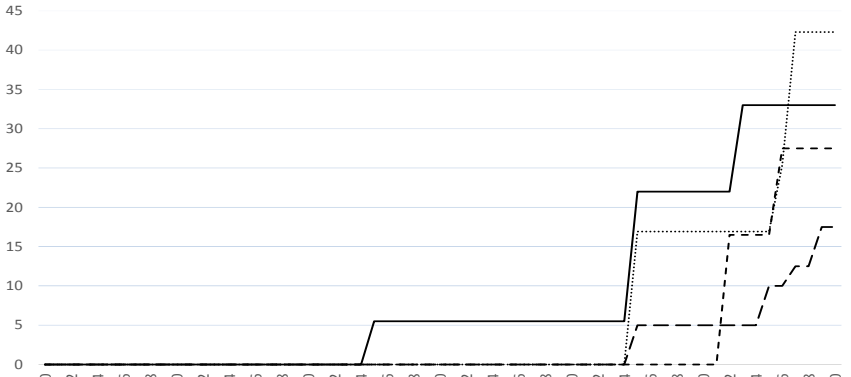

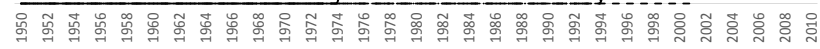
- -smoke-free air Year

-..... bans on advertising \& promotion
- - smoking cessation \& treatment policies

France

50
45
40
35
30
25
20
15
10
5
0

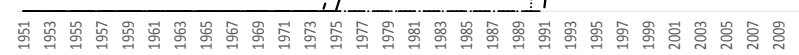

- -smoke-free air

Year

-..... bans on advertising \& promotion

Ireland

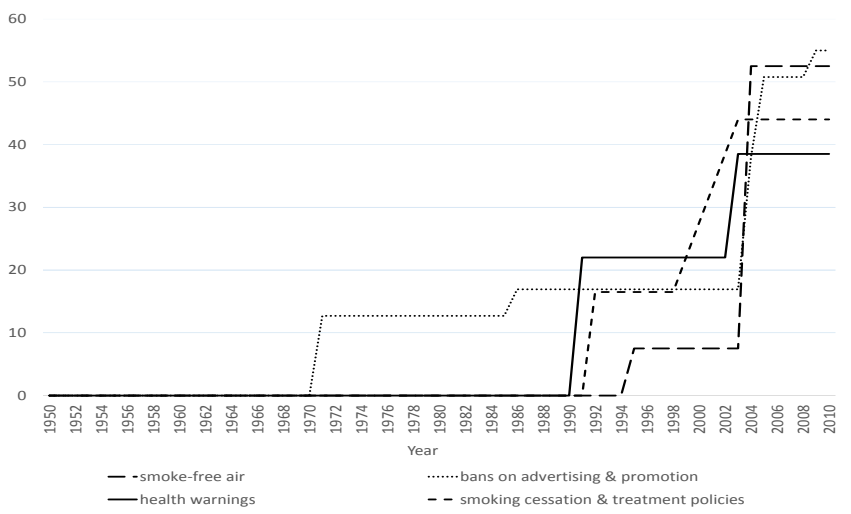

Finland

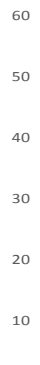

0

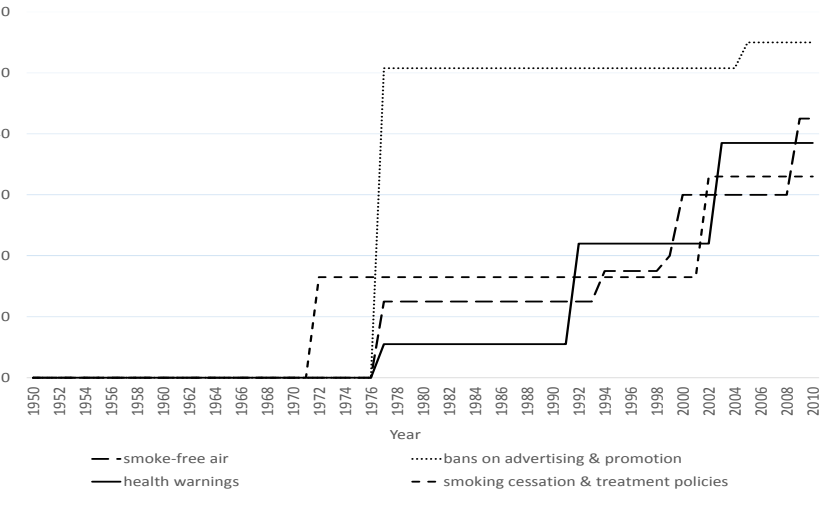

Germany

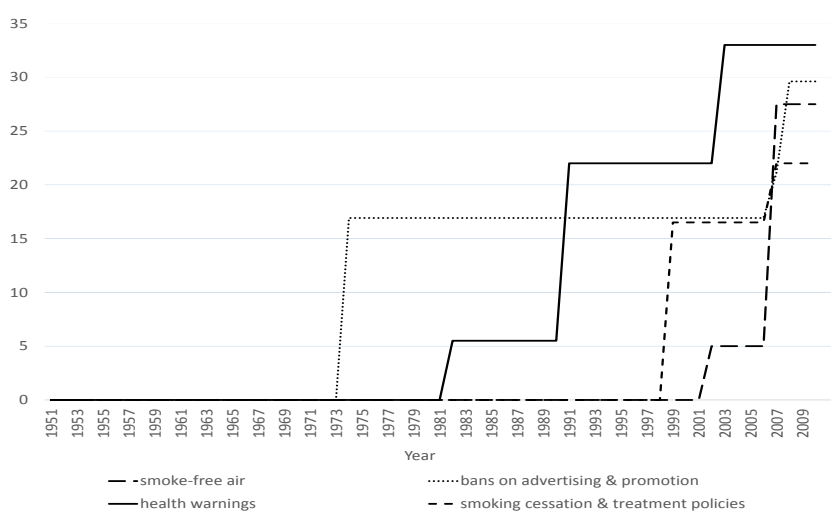

Italy

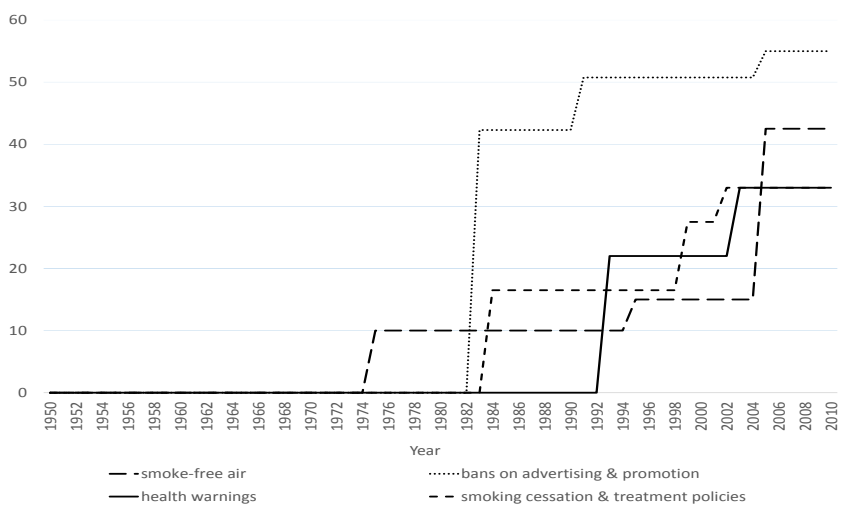


Figure 2 continued.

Netherlands

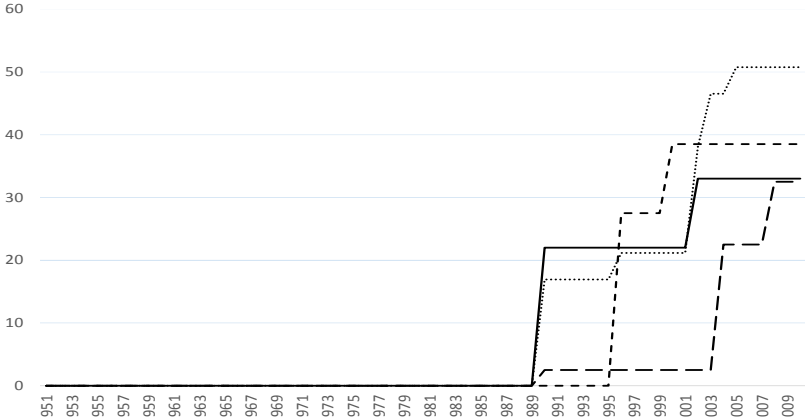

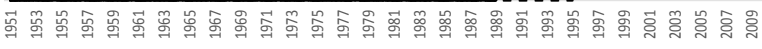
— -smoke-free air

-.... bans on advertising \& promotion

Spain

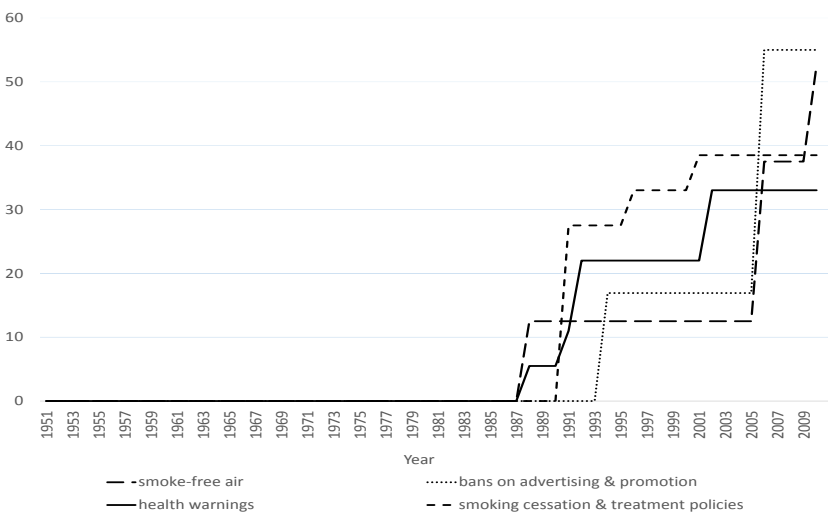

United Kingdom

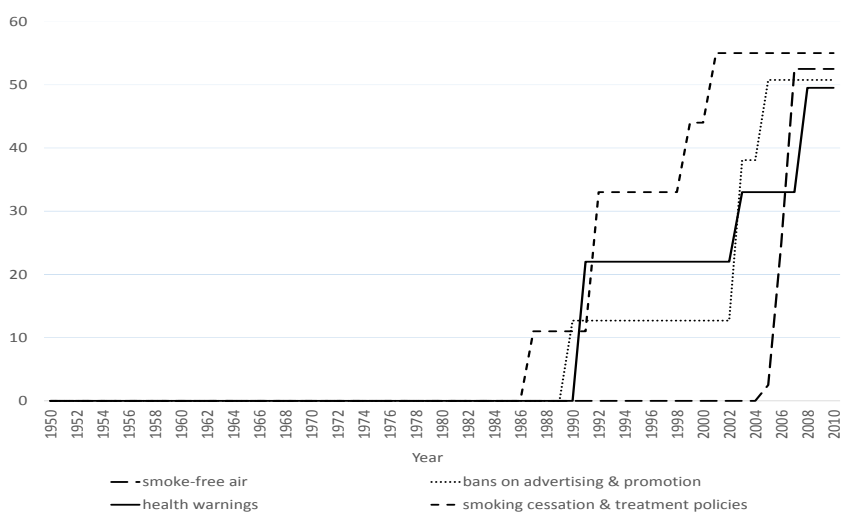

Portugal

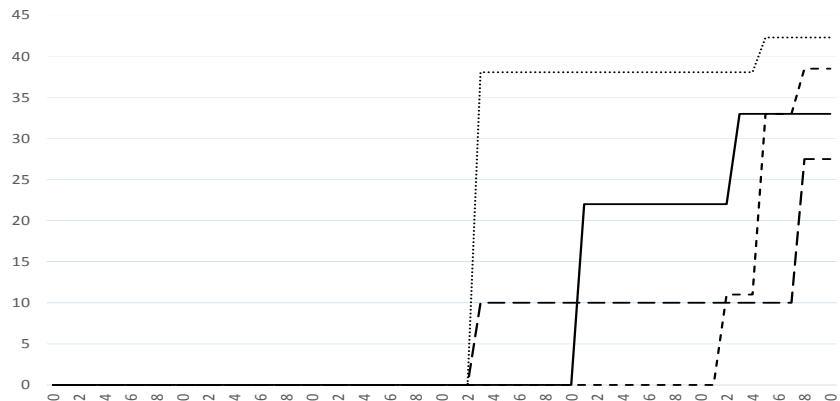

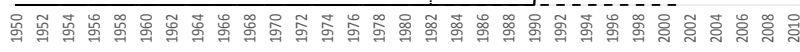

- -smoke-free air

....... bans on advertising \& promotion

- - smoking cessation \& treatment policies

Sweden

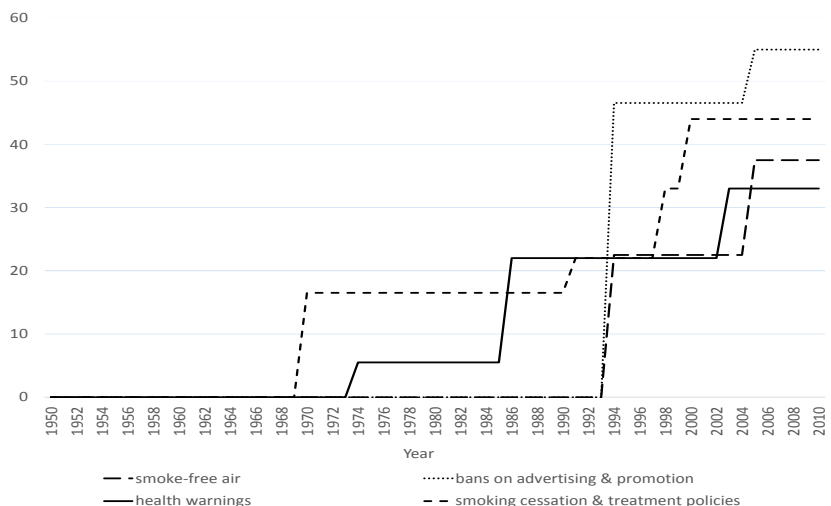


Figure 3: Starting rates and cumulative starting probability of smoking.

\section{Austria}
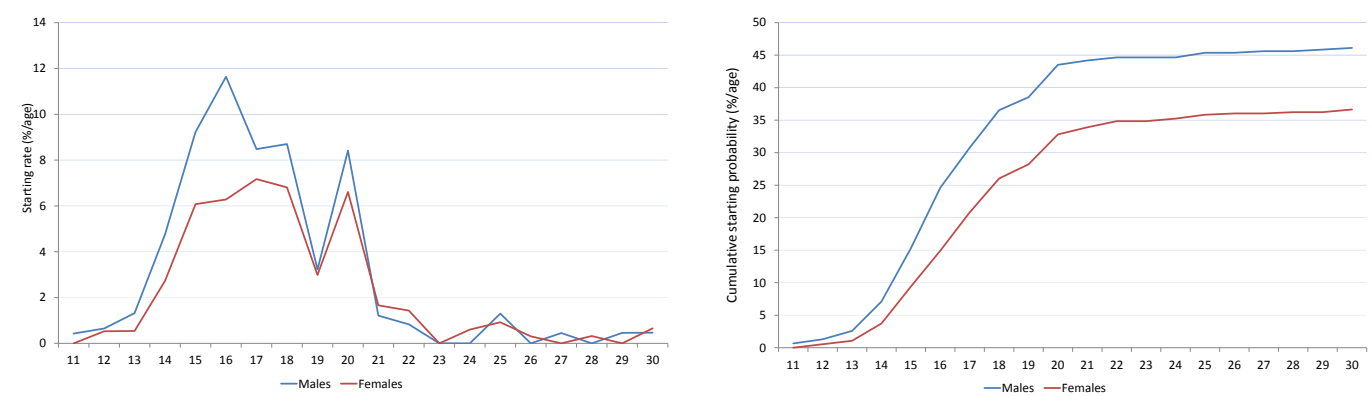

Germany
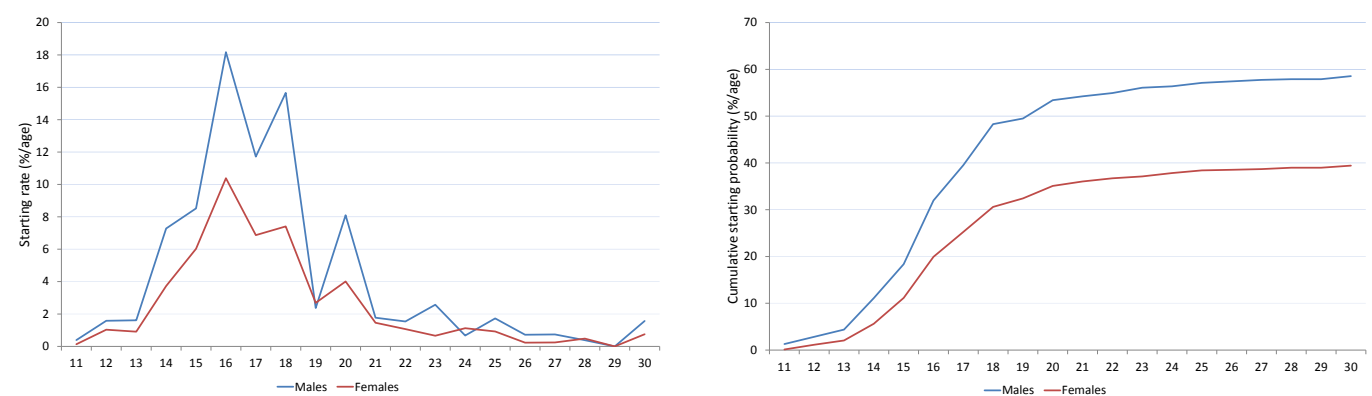

Spain
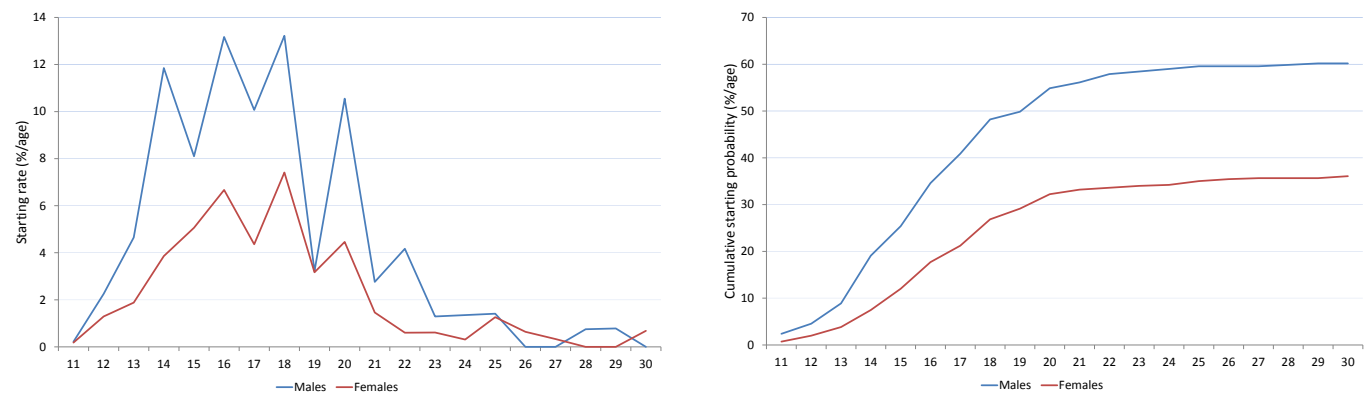

Finland
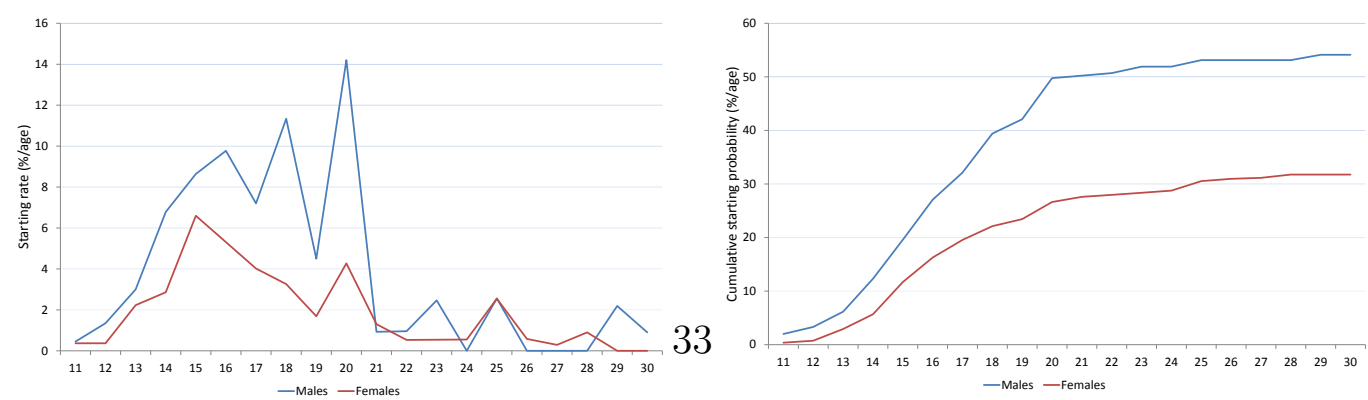
Figure 3 continued.

\section{France}
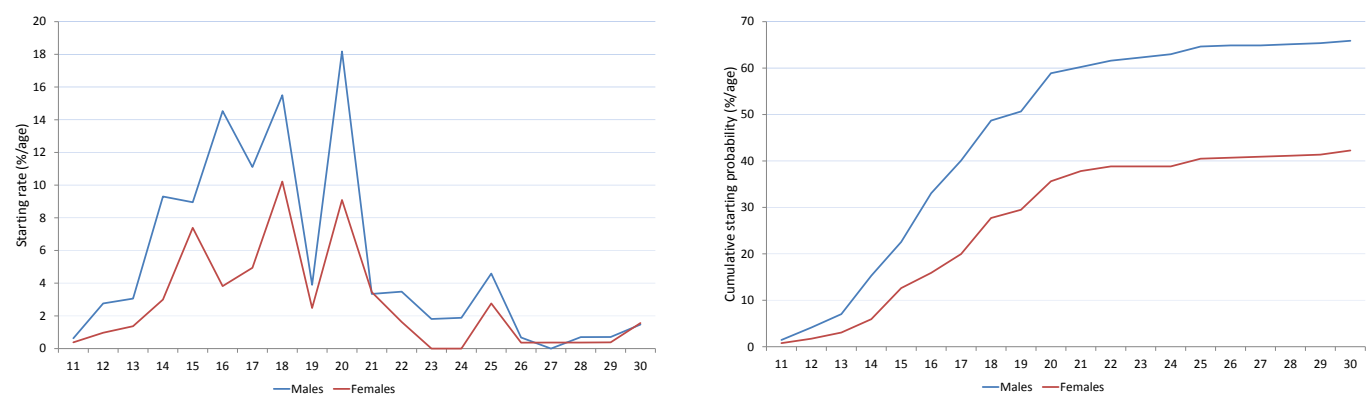

Ireland
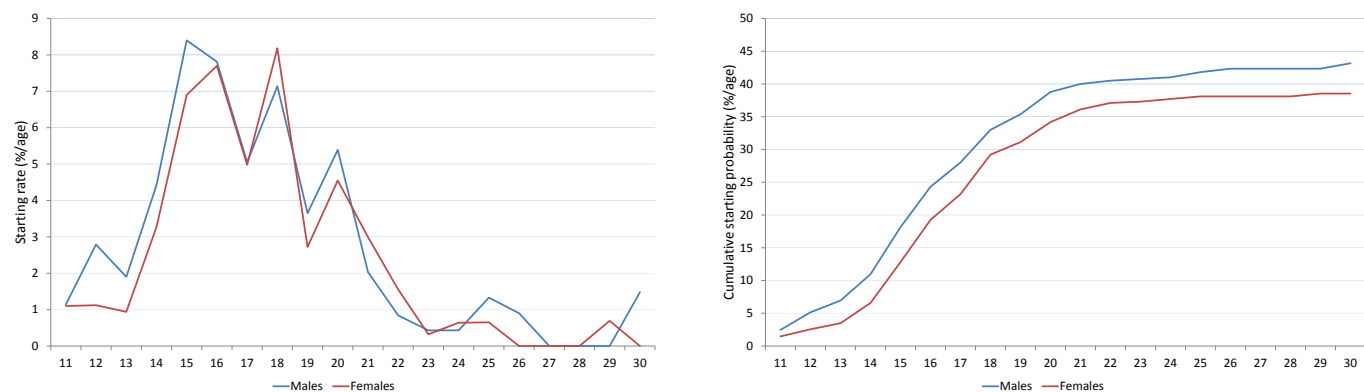

Italy
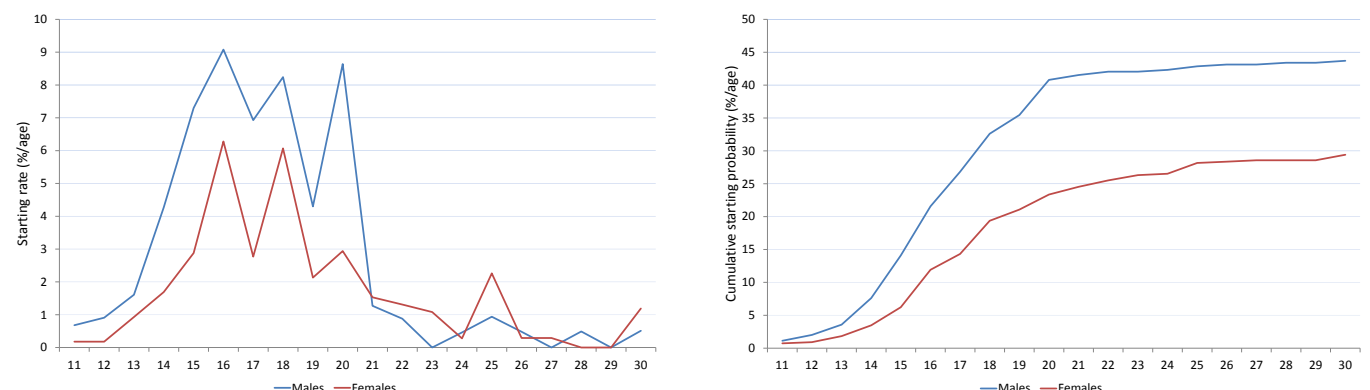

Netherlands
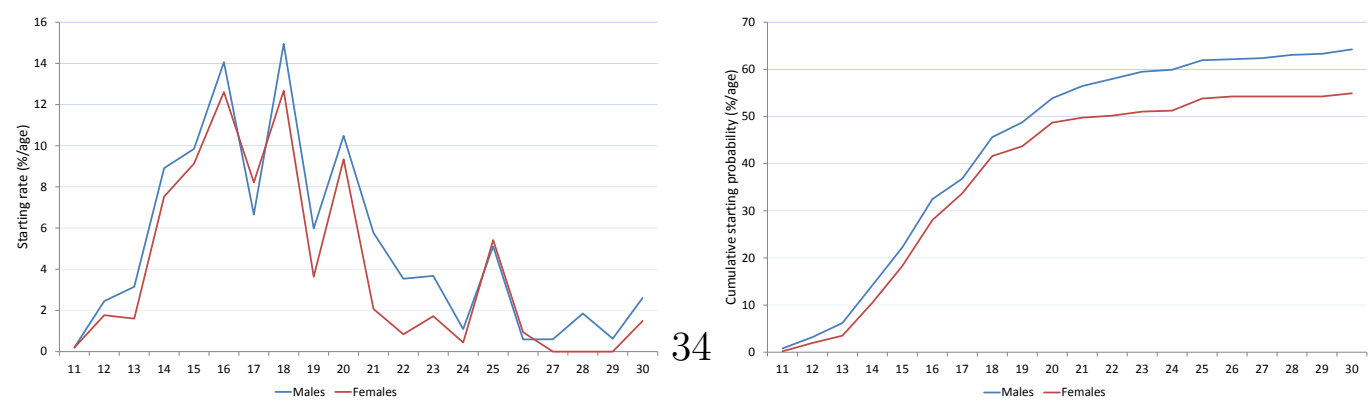
Figure 3 continued.

Portugal
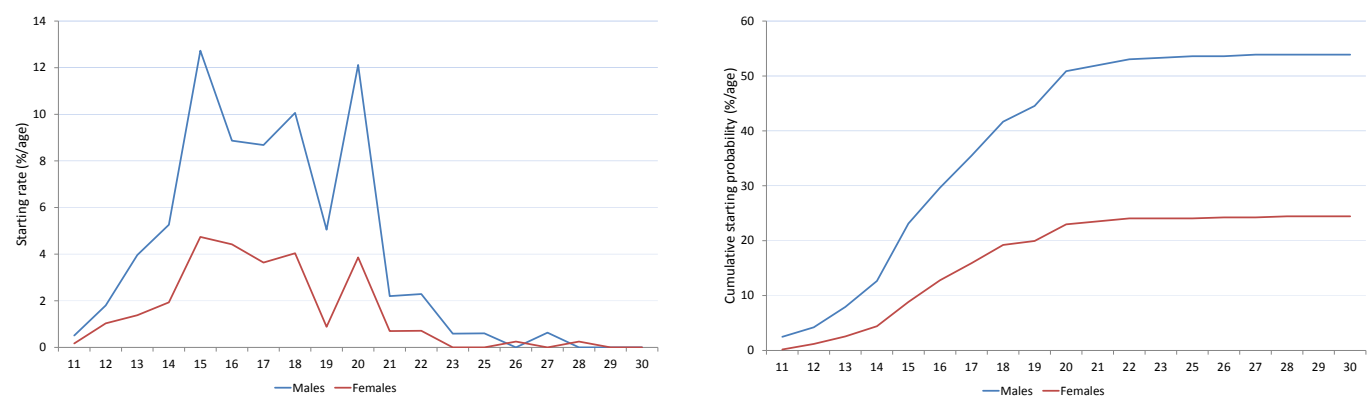

Sweden
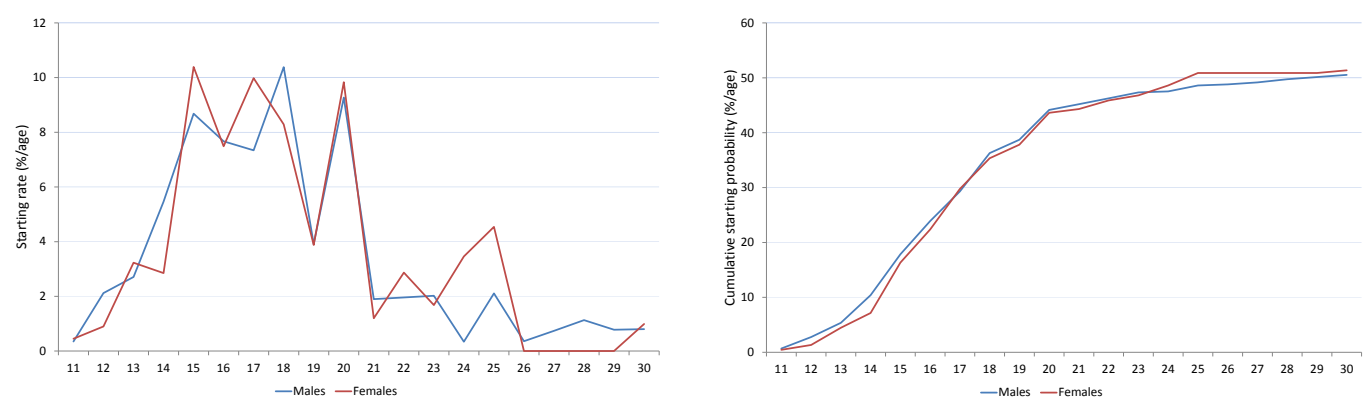

United Kingdom
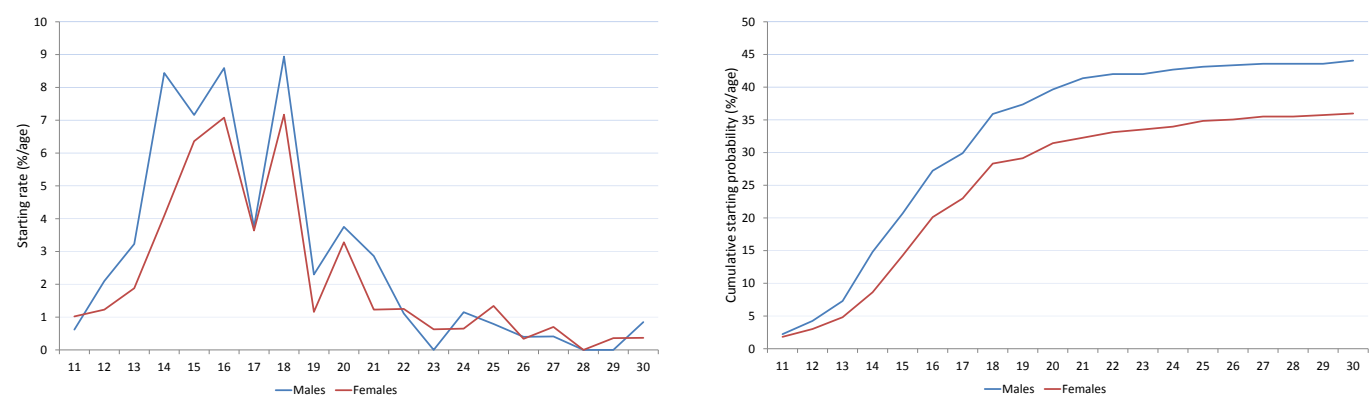